\title{
Blood Transfusion and Increased Perioperative Risk in Coronary Artery Bypass Grafts
}

Igor C. Campos ${ }^{1}$, MD; Valessa Tanganelli ${ }^{1}$, MD; Hugo P. Maues ${ }^{1}$, MD; Marcio C. M. Coelho' ${ }^{1}$, MD; Fernanda A. Martins ${ }^{1}$, MD; Giovana Munhoz' , MD; Julyana G. T. Egito' , MD; Hayala C. C. Souza²; Cássio M. C. Giannini ${ }^{3}$, MD; Pedro S. Farsky4, $\mathrm{MD}, \mathrm{PhD}$

\section{Abstract}

Objective: To correlate blood transfusions and clinical outcomes during hospitalization in coronary artery bypass grafting surgery (CABG).

Methods: Transfusion, clinical and hematological data were collected for 1,378 patients undergoing isolated or combined CABG between January 2011 and December 2012. The effect of blood transfusions was evaluated through multivariate analysis to predict three co-primary outcomes: composite ischemic events, composite infectious complications and hospital mortality. Because higher risk patients receive more transfusions, the hospital mortality outcome was also tested on a stratum of low-risk patients to isolate the effect of preoperative risk on the results.

Results: The transfusion rate was $63.9 \%$. The use of blood products was associated with a higher incidence of the three co- primary outcomes: composite infectious complications (OR 2.67, $95 \% \mathrm{Cl} 1.70$ to $4.19 ; P<0.001$ ), composite ischemic events (OR 2.42, $95 \% \mathrm{Cl} 1.70$ to $3.46 ; P<0.001$ ) and hospital mortality (OR $3.07,95 \% \mathrm{Cl}$ 1.53 to $6.13 ; P<0.001)$. When only patients with logistic EuroSCORE $\leq 2 \%$ were evaluated, i.e., low-risk individuals, the mortality rate and the incidence of ischemic events and infectious complications composites remained higher among the transfused patients $[6 \%$ vs. $0.4 \%(P<0.001), 11.7 \%$ vs. $24,3 \%(P<0.001)$ and $6.5 \%$ vs. $12.7 \%$ $(P=0.002)$, respectively].

Conclusion: The use of blood components in patients undergoing CABG was associated with ischemic events, infectious complications and hospital mortality, even in low-risk patients.

Keywords: Blood transfusion. Bloodless Medical and Surgical Procedures. Myocardial Revascularization. Coronary Artery Bypass.

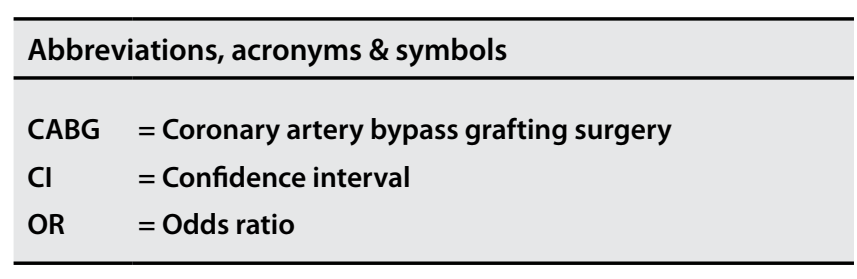

\section{INTRODUCTION}

The use of blood products in cardiac surgery is a known risk factor for adverse events during the perioperative period. Unnecessary transfusions can cause further increases in surgical risk and complications. Blood transfusion criteria in this scenario are not yet well established and exhibit variability between different centers and among professionals at the same center.

IInstituto Dante Pazzanese de Cardiologia, São Paulo, SP, Brazil. ¿Laboratory of Statistics and Epidemiology, Instituto Dante Pazzanese de Cardiologia, São Paulo, SP, Brazil.

${ }^{3}$ Fundação Pró-Sangue, Instituto Dante Pazzanese de Cardiologia, São Paulo, SP, Brazil. ${ }^{4}$ Instituto Dante Pazzanese de Cardiologia; Universidade de Santo Amaro (UNISA), São Paulo, SP, Brazil.

This study was carried out at the Instituto Dante Pazzanese de Cardiologia, São Paulo, SP, Brazil.
Several studies, mostly observational, have demonstrated an association between pre- and intraoperative anemia and increased morbidity and mortality after cardiac surgery ${ }^{[1,2]}$. A drop in hematocrit in the absence of shock has been the main indication for transfusion in critically ill patients, and in up to $29 \%$ of these cases there is no clear justification for transfusion ${ }^{[3]}$.

A potential indication of transfusion is the association between severe anemia and hypoxemia, which may increase postoperative risk, but this theory is not confirmed.

Patients receiving transfusions are usually at a greater preoperative risk, added with the risk of the event leading to transfusion. Preliminary studies show higher mortality rates, ischemic and infectious outcomes, however, these previous studies are not corrected for the individual risk of patients. Furthermore, these studies evaluated patients submitted to
No financial support.

No conflict of interest.

Correspondence Address:

Pedro Silvio Farsky

Rua Alberto Faria, 248 - Alto de Pinheiros - São Paulo, SP, Brazil - Zip code: 05459-000 E-mail: pedro.farsky@gmail.com

Article received on February 21 2017. Article accepted on May 22nd, 2017. 
general surgery, and when evaluated patients undergoing cardiac surgery, are not specifically for coronary artery bypass surgery $(\mathrm{CABG})^{[4-6]}$.

This study evaluates the association between blood transfusions and hospital morbidity and mortality in patients undergoing CABG (isolated or combined); furthermore, is analyzed a subgroup of low-risk patients, in order to minimize the effects of the greater preoperative risk of the transfused patients, identified by a low Logistic EuroSCORE.

\section{METHODS}

Consecutive patients undergoing isolated or combined CABG between January $1^{\text {st }} 2011$ and December $31^{\text {st }} 2012$ were included in the study. Patients aged $\leq 18$ years or those who were not undergoing surgery with a cardiopulmonary bypass were not selected.

The lowest hemoglobin values measured between a patient's departure from the operating room until 10 days after surgery were included. Intraoperative hemoglobin data were not included.

The transfusion of blood products (packed red cells, packed platelets, fresh frozen plasma and cryoprecipitate), conducted between 5 days before and 10 days after CABG, was considered to be of primary interest.

Blood transfusions were performed when hemoglobin levels fell below $7 \mathrm{~g} / \mathrm{dL}$ or in critical clinical conditions, at the physician's discretion.

Three co-primary outcomes were pre-specified: infectious outcomes, ischemic outcomes, and hospital death.

An infectious outcome was defined as a composite of respiratory infection, wound infection and/or sepsis. An ischemic outcome was defined as a composite of stroke, transient ischemic attack, acute myocardial infarction and/or acute renal failure (an increase in the creatinine value of at least $50 \%$ as per the Acute Renal Injury Network ${ }^{[7]}$ ). Hospital mortality was defined as death that occurred within 30 days of surgery or during hospitalization ${ }^{[8]}$.

Demographic characteristics and comorbidities were obtained from institutional databases, and data were organized by absolute and relative frequencies (qualitative variables) and by mean and standard deviation (quantitative variables).

Information infrequently missing from the database $(<1 \%)$ was redistributed in the median or most frequent category. Information more frequently missing (> 1\%) was considered void and was not included in analyses. The study was approved by the Ethics Committee of each institution involved.

\section{Statistical Analysis}

To compare quantitative variables from transfused and nontransfused patients, Student's-t and Mann-Whitney tests were used according to the distribution of variables. To compare groups by categorical variables, Fisher's exact test was used.

Univariate analysis was performed between the transfusion and non-transfusion groups using preoperative variables. These variables were included, with data on the transfusion of blood products, in a multivariate logistic regression model to predict mortality, infectious outcomes and ischemic outcomes. The odds ratio (OR) and 95\% confidence interval (Cl) values were reported.

\section{RESULTS}

A total of 1,389 patients underwent CABG during the study period. Eleven patients had no transfusion data and were excluded. Clinical characteristics are described in Table 1.

Among the 1,378 patients included, 498 (36.1\%) did not receive any type of blood product transfusion and 880 (63.9\%) received one or more. Of these, 63 (4.6\% of the total) individuals received only blood components other than packed red blood cells, and 817 (59.3\%) received at least one packed red blood cell product, with or without other blood products. The percentage of patients using each of the blood products studied and the mean numbers of transfused bags are listed in Table 2.

The transfused patients were older, had lower body weight, preoperative hemoglobin values and minimum hemoglobin values in the first 10 days after surgery, and had higher logistical EuroSCOREs than control patients. Anoxia and cardiopulmonary bypass times were significantly longer in this group. The proportion of women, number of patients with stage 4 or 5 kidney failure, and incidence of combined surgery and triarterial or trunk injuries were significantly higher among transfused patients.

The incidence of composite infectious outcomes among transfusion patients was $16.1 \%$ compared to $6 \%$ among the nontransfused (OR 3; 95\% Cl 1.99 to $4.53 ; P<0.001$ ]. This association was also significant when each of its components was evaluated [sepsis 3\% vs. $0.6 \%$ (OR 5.02, 95\% Cl 1.51 to 16.68; $P<0.001$ ), respiratory infection $8.6 \%$ vs. $2.6 \%$ (OR 3.53, 95\% Cl 1.94 to 6.42 ; $P<0.001$ ), surgical wound infection $9.7 \%$ vs. $3.6 \%$ (OR $2.77,95 \% \mathrm{Cl}$ 1.59 to $4.80 ; P<0.001)]$.

Ischemic outcomes occurred in $29.4 \%$ of the transfused group and in $12.6 \%$ of the non-transfused (OR 2.91, 95\% Cl 2.13 to $3.98 ; P<0.001)$. As with infectious outcomes, there was also an association between transfusion and each component of ischemic outcomes [kidney failure $21 \%$ vs. 9.3\% (OR 2.58, 95\% Cl 1.81 to $3.68 ; P<0.001)$, stroke $4.1 \%$ vs. $1.8 \%$ (OR $2.32,95 \% \mathrm{Cl} 1.11$ to $4.85 ; P<0.001)$, acute perioperative myocardial infarction $8 \%$ vs. $2.2 \%$ (OR $3.83,95 \% \mathrm{Cl} 2.01$ to $7.30 ; P<0.001)$ ].

Hospital mortality among transfused patients was significantly higher than among non-transfused patients [10\% vs. $2.2 \%$ (OR $4.92,95 \% \mathrm{Cl} 2.6$ to $9.3 ; P<0.001)$ ].

In the low-risk group, patients identified by logistic EuroSCORE $\leq 2 \%$ (252 transfused and 260 non-transfused patients), had a mortality of $6 \%$ vs. $0.4 \%(P<0.001)$ for the transfused and nontransfused group, ischemic outcome of $11.7 \%$ vs. $24.3 \%(P<0.001)$ and infectious outcome $6.5 \%$ vs. $12.7 \%(P=0.002)$.

When adjusted by a multivariate logistic model, the association between transfusion and the three co-primary outcomes was maintained in relation to composite infectious outcomes (OR 2.67, $95 \% \mathrm{Cl} 1.70$ to $4.19 ; P<0.001$ ), composite ischemic outcomes (OR $2.42,95 \% \mathrm{Cl} 1.70$ to $3.46 ; P<0.001$ ) and hospital mortality (OR 3.07, $95 \%$ Cl 1.53 to $6.13 ; P<0.001$ ) (Figure 1 ).

In our study, other variables were identified as independent predictors of the three outcomes, as follows: mortality (creatinine clearance $<30 \%$, age $>75$ years, diabetes mellitus, family history 
Table 1. Population characteristics $(n=1,378)$.

\begin{tabular}{|c|c|c|c|}
\hline Characteristic & Non-transfused $(n=498)$ & Transfused $(n=880)$ & $P$ value \\
\hline \multicolumn{4}{|l|}{ Age, n (\%) } \\
\hline$<65$ years & $336(67.5)$ & $441(50.1)$ & $<0.001$ \\
\hline 65 to 75 years & $136(27.3)$ & $308(35)$ & - \\
\hline$\geq 75$ years & $26(5.2)$ & $131(14.9)$ & - \\
\hline Female, n (\%) & $77(15.5)$ & $354(40.2)$ & $<0.001$ \\
\hline Preoperative $\mathrm{Hb}, \mathrm{g} / \mathrm{dL}$ & $14.4 \pm 1.5$ & $13.6 \pm 1.7$ & $<0.001$ \\
\hline Minimum $\mathrm{Hb}, \mathrm{g} / \mathrm{dL}$ & $8.9 \pm 1.3$ & $7.9 \pm 1.2$ & $<0.001$ \\
\hline Weight, kg & $80.6 \pm 14.1$ & $72.8 \pm 14.1$ & $<0.001$ \\
\hline Anoxia time, minutes & $50.6 \pm 20.6$ & $61.7 \pm 25.1$ & $<0.001$ \\
\hline ECC time, minutes & $74 \pm 29$ & $93 \pm 38$ & $<0.001$ \\
\hline Logistical EuroSCORE (\%) & $3.18 \pm 4.54$ & $5.82 \pm 7.9$ & $<0.001$ \\
\hline $\mathrm{CrCl} \leq 30 \mathrm{mg} / \mathrm{dL}, \mathrm{n}(\%)$ & $5(1.1)$ & $29(3.5)$ & 0.01 \\
\hline$E F<50 \%, n(\%)$ & $181(36.8)$ & $322(37)$ & 0.95 \\
\hline Diabetes mellitus, n (\%) & $199(40)$ & $371(42.2)$ & 0.45 \\
\hline $\mathrm{SAH}, \mathrm{n}(\%)$ & $429(86.1)$ & $764(86.8)$ & 0.74 \\
\hline \multicolumn{4}{|l|}{ Smoker, n (\%) } \\
\hline Non-smoker & $212(42.6)$ & $418(47.5)$ & 0.1 \\
\hline Current smoker & $111(22.3)$ & $160(18.2)$ & - \\
\hline Ex-smoker (> 1 year) & $175(35.1)$ & $302(34.3)$ & - \\
\hline COPD, n (\%) & $22(4.4)$ & $43(4.9)$ & 0.79 \\
\hline Prior stroke/TIA, n (\%) & $25(5)$ & $54(6.1)$ & 0.47 \\
\hline Carotid disease (> 50\%), n (\%) & $20(4)$ & $54(6.1)$ & 0.1 \\
\hline Peripheral vascular disease, n (\%) & $38(7.6)$ & $82(9.3)$ & 0.32 \\
\hline AMI in last 30 days, n (\%) & $64(12.9)$ & $144(16.4)$ & 0.08 \\
\hline Combined MR, n (\%) & $54(10.8)$ & $188(21.4)$ & $<0.001$ \\
\hline \multicolumn{4}{|l|}{ Affected arteries, n (\%) } \\
\hline Uni or biarterial & $146(30.3)$ & $205(24.4)$ & 0.02 \\
\hline Triarterial or trunk & $336(69.7)$ & $635(75.6)$ & - \\
\hline
\end{tabular}

$\mathrm{AMI}=$ acute myocardial infarction; $\mathrm{COPD}=$ chronic obstructive pulmonary disease; $\mathrm{CrCl}=\mathrm{creatinine}$ clearance; $\mathrm{ECC}=$ extracorporeal circulation; $\mathrm{EF}=$ =jection fraction; $\mathrm{Hb}=$ hemoglobin; $\mathrm{MR}=$ =myocardial revascularization surgery; $\mathrm{SAH}=$ systemic arterial hypertension; $\mathrm{TIA}=$ transitory ischemic attack

of coronary artery disease and current smoking), infectious outcomes (creatinine clearance $\leq 30 \%$, age $\geq 75$ years, chronic obstructive pulmonary disease and high body mass index) and ischemic outcomes (family history of coronary artery disease and female gender).

Among the 17 surgeons who performed CABG during the study period, excluding those who performed fewer than 10 procedures (5 professionals), the transfusion rate ranged from $53 \%$ to $79 \%(P<0.001)$.

Table 3 shows data from the multivariate logistic analysis for the prediction of the three co-primary outcomes.

\section{DISCUSSION}

This retrospective study of 1,378 consecutive patients undergoing $C A B G$ revealed an association between blood transfusion and composite infectious and ischemic outcomes and mortality. Transfused patients are, as a group, at higher surgical risk; however, when only low-risk patients were selected by EuroSCORE, mortality remained high in the transfused group.

A blood product transfusion rate of $63.9 \%$ was found in this study. When only patients receiving packed red blood cells, with or without other blood components, were considered, the proportion 
was $59.3 \%$. This value is consistent with the findings of other studies ${ }^{[9,10]}$. However, a downward trend in transfusion rates and the number of transfused bags has been observed in recent years ${ }^{[11]}$.

We used a $7 \mathrm{~g} / \mathrm{dL}$ as a threshold to transfusion, but, in case of critical clinical events, the transfusion was indicated at higher levels of hemoglobin.

Table 2. Transfusion rates and mean transfused units.

\begin{tabular}{l|c|c}
\hline & n (\%) & Mean units \pm SD \\
\hline Packed red blood cells & $817(59.3)$ & $2.37 \pm 1.68$ \\
\hline Packed platelets & $157(11.4)$ & $8.34 \pm 6.91$ \\
\hline Cryoprecipitate & $82(6)$ & $8.04 \pm 3.45$ \\
\hline Fresh frozen plasma & $274(19.9)$ & $2.77 \pm 2.12$ \\
\hline
\end{tabular}

$\mathrm{SD}=$ standard deviation

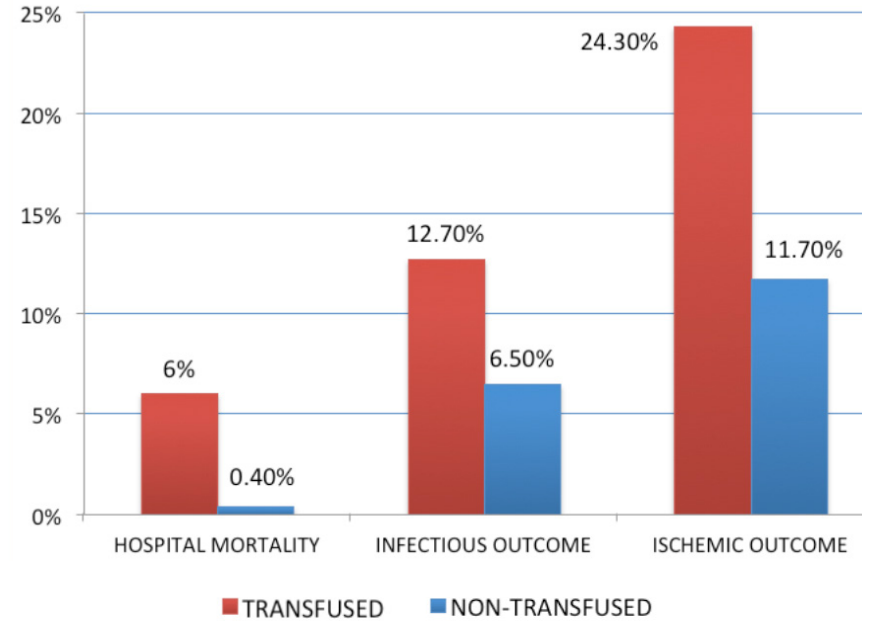

Fig. 1 - Outcomes in patients with EurOSCORE $\leq 2$.

Table 3. Multivariate logistic analysis for the prediction of three co-primary outcomes.

\begin{tabular}{|c|c|c|c|c|c|c|}
\hline & \multicolumn{2}{|c|}{ Mortality } & \multicolumn{2}{|c|}{ Infectious outcome } & \multicolumn{2}{|c|}{ Ischemic outcome } \\
\hline & OR $(95 \% \mathrm{Cl})$ & $P$ & OR $(95 \% \mathrm{Cl})$ & $P$ & OR $(95 \% \mathrm{Cl})$ & $P$ \\
\hline Transfusion & $3.07(1.53-6.13)$ & 0.002 & $2.67(1.7-4.19)$ & $<0.001$ & $2.42(1.7-3.46)$ & $<0.001$ \\
\hline \multicolumn{7}{|l|}{ Age } \\
\hline $65-75$ years & $1.38(0.79-2.41)$ & 0.257 & $1.36(0.91-2.02)$ & 0.136 & $1.22(0.88-1.69)$ & 0.231 \\
\hline$\geq 75$ years & $3.37(1.75-6.48)$ & $<0.001$ & $2.24(1.32-3.82)$ & 0.003 & $1.43(0.9-2.26)$ & 0.126 \\
\hline Female & $1.07(0.64-1.79)$ & 0.795 & $1.36(0.92-2.01)$ & 0.119 & $1.47(1.07-2.02)$ & 0.017 \\
\hline $\mathrm{BMI}, \mathrm{kg} / \mathrm{m}^{2}$ & $1.02(0.97-1.07)$ & 0.434 & $1.11(1.07-1.15)$ & $<0.001$ & $1.03(0.99-1.06)$ & 0.114 \\
\hline Preoperative $\mathrm{Hb}, \mathrm{g} / \mathrm{dL}$ & $0.91(0.78-1.06)$ & 0.223 & $1.06(0.94-1.19)$ & 0.319 & $0.96(0.87-1.05)$ & 0.37 \\
\hline $\mathrm{CrCl} \leq 30 \mathrm{mg} / \mathrm{dL}$ & $2.98(1.11-8.02)$ & 0.030 & $2.99(1.24-7.23)$ & 0.015 & $0.42(0.15-1.16)$ & 0.93 \\
\hline $\mathrm{SAH}$ & $2.32(0.89-6.08)$ & 0.086 & $1.46(0.77-2.79)$ & 0.245 & $1.54(0.96-2.49)$ & 0.076 \\
\hline Diabetes mellitus & $1.73(1.08-2.78)$ & 0.023 & $1.25(0.88-1.78)$ & 0.206 & 1.29 (0.97-1.72) & 0.08 \\
\hline Family history of CAD & $2.36(1.11-5)$ & 0.025 & $0.91(0.45-1.84)$ & 0.797 & $1.81(1.1-2.96)$ & 0.019 \\
\hline \multicolumn{7}{|l|}{ Tobacco use } \\
\hline Ex-smoker & $1.17(0.68-2.03)$ & 0.566 & $0.99(0.66-1.49)$ & 0.975 & $0.85(0.61-1.18)$ & 0.328 \\
\hline Current smoker & $2(1.05-3.78)$ & 0.034 & $1.5(0.93-2.42)$ & 0.096 & $1.08(0.72-1.61)$ & 0.712 \\
\hline COPD & $1.33(051-3.5)$ & 0.558 & $2.17(1.08-4.37)$ & 0.03 & $1.49(0.79-2.8)$ & 0.221 \\
\hline Prior stroke & $1.72(0.71-4.19)$ & 0.229 & $1.27(0.61-2.63)$ & 0.527 & $1.34(0.73-2.48)$ & 0.345 \\
\hline Prior TIA & $1.14(013-9.85)$ & 0.906 & $0.53(0.06-4.35)$ & 0.555 & $0.29(0.04-2.37)$ & 0.247 \\
\hline Carotid disease $\geq 50 \%$ & $0.54(0.19-1.51)$ & 0.242 & $1.53(0.79-2.94)$ & 0.206 & $1.3(0.72-2.34)$ & 0.38 \\
\hline Peripheral vascular disease & $1.8(0.9-3.61)$ & 0.096 & $1.35(0.76-2.4)$ & 0.302 & $1.29(0.79-2.11)$ & 0.311 \\
\hline Prior AMI & $1.29(0.79-2.11)$ & 0.311 & $1.2(0.84-1.72)$ & 0.324 & $1.07(0.8-1.44)$ & 0.643 \\
\hline Triarterial or trunk injury & $1(0.58-1.73)$ & 0.996 & $1.26(0.84-1.91)$ & 0.267 & $1.21(0.87-1.68)$ & 0.267 \\
\hline$E F<50 \%$ & $0.98(0.6-1.62)$ & 0.949 & $0.91(0.63-1.32)$ & 0.63 & $0.87(0.64-1.18)$ & 0.354 \\
\hline
\end{tabular}

$\mathrm{AMI}=$ acute myocardial infarction; $\mathrm{BMI}=$ body mass index; $\mathrm{CAD}=$ coronary artery disease; $\mathrm{Cl}$ 95\%=95\% confidence interval; $\mathrm{COPD}=$ chronic obstructive pulmonary disease; $\mathrm{CrCl}=$ creatinine clearance; $\mathrm{EF}=$ ejection fraction; $\mathrm{Hb}=$ hemoglobin; $\mathrm{OR}=\mathrm{odds}$ ratio; $\mathrm{SAH}=$ systemic arterial hypertension; TIA=transitory ischemic attack 
There was great variability in transfusion frequency among different surgeons, although a significant portion of these transfusions was performed in the intensive care unit.

As expected, transfused patients were a group of patients with higher risk of death and comorbidities. However, even in the lowrisk group, identified as a low EuroSCORE risk (below 2\%), there was an association between transfusion and morbidity and mortality.

\section{Composite Infectious Outcomes}

A composite infectious outcome, defined as sepsis, respiratory infection and surgical wound infection, was significantly more prevalent among patients undergoing blood transfusions (16.1\% vs. 6\%). This relationship has been demonstrated in several publications ${ }^{[12]}$ and is believed to be related to the socalled "immunomodulating effect" of transfusion. This includes changes in blood cell compositions, such as a decreased number of circulating lymphocytes, changes in the Thelper/T suppressor lymphocyte ratio and immune cell activation ${ }^{[13]}$. These changes ultimately predispose the individual to susceptibility to infectious agents, particularly bacteria. Perioperative blood transfusion enhances the already established inflammatory status caused by cardiopulmonary bypass and surgical trauma, increasing the levels of circulating cytokines by up to 15 times $^{[14]}$.

Some authors have suggested that the leukodepletion of blood products decreases cytokine levels, reducing the deleterious effects of transfusion, but this has not translated into improved clinical outcomes in subsequent studies ${ }^{[15]}$. Our study did not include this analysis due to its low frequency in our cohort and because it is not a common practice in Brazil.

\section{Composite Ischemic Outcomes}

Following the findings of previous studies that have shown an association between transfusion and tissue ischemia in patients undergoing $C A B G$, our results demonstrated a higher incidence of composite kidney failure, stroke and acute perioperative myocardial infarction among transfused patients (29.4\% vs. $12.6 \%)$. How blood transfusions lead to ischemic complications in these patients is not fully understood, but it is believed that the previously described inflammatory changes are responsible for these findings. Additional molecular, biochemical and structural changes caused by the storage of bags lead to decreased concentrations of 2 3-diphosphoglycerate, fragility and lower red blood cell distensibility, reducing their capacity to supply oxygen to tissues ${ }^{[16]}$.

\section{Mortality}

The risk of death was three times higher among transfused patients when compared to the non-transfused. The former significantly higher average EuroSCORE; older age; a higher prevalence of combined surgeries, severe coronary lesions, and kidney failure; and lower hemoglobin levels indicate that this is a group with higher preoperative morbidity. This observation could raise questions about the real effect of transfusion on outcomes. However, when adjusted for these and other variables, transfusion remains an independent risk factor for mortality and combined outcomes.
Other information contradicting the hypothesis that the higher mortality in the transfused group stems from patients' conditions being more severe was provided by an analysis of mortality in low-risk strata. When only patients with low logistic EuroSCORE $(\leq 2 \%)$ were evaluated in both groups, the mortality rate among the transfused remained significantly higher.

\section{Low-Risk Group}

The highest mortality rate, infection and ischemic outcomes in the transfusion group may not be due to transfusion, but due to complications after CABG in a high-risk group. This are important confounders in studies evaluating transfusion after CABG. Patients receiving blood products are part of a higher risk group, due to their high number of comorbidities. In addition, it is the situation that caused the major bleeding, with its tissue hypoxia complications, an additional surgical procedure to correct the bleeding and the possible adverse effects of transfusion. Transfused patients more frequently require inotropic and mechanical support. Despite careful statistical adjustments, it is possible that these factors caused additional risk.

When patients with low baseline risk profiles were selected by logistic EuroSCORE $<2 \%$, confounding factors were reduced. In this scenario, significantly higher mortality remained in the group receiving transfusions, as well as higher ischemic and infectious outcomes, possibly due to tissue hypoxia complications, could be a possibility caused by anemia/hypoperfusion associated with the deleterious effects of transfusion.

A recent prospective, randomized study ${ }^{[17]}$ testing the use of liberal or restrictive transfusion strategies, defined by the use of a threshold for transfusion of $9.0 \mathrm{~g} / \mathrm{dL}$ or $7.0 \mathrm{~g} / \mathrm{dL}$, did not show differences between the two subgroups. However, the difference in hemoglobin levels between the groups was only $1 \mathrm{~g} / \mathrm{dL}$.

As expected, the minimum postoperative hemoglobin level in transfused individuals was significantly lower than in patients who did not receive transfusions ( $7.9 \pm 1.2$ vs. 8.9 \pm 1.3$)$. These values, rather than a patient's actual clinical indication, guide transfusion indications in the operating room, especially in surgery involving cardiopulmonary bypass ${ }^{[18]}$. The use of a restrictive transfusion strategy has proven to be well tolerated by patients in various studies. In a randomized clinical trial of patients undergoing CABG, Bracey et al. ${ }^{[19]}$ reported that a reduction in the transfusion hemoglobin threshold to $8 \mathrm{mg} / \mathrm{dL}$ did not negatively affect outcomes and resulted in lower costs. In a large multicenter study of critically ill patients not undergoing cardiac surgery, Hebert et al. ${ }^{[20]}$ found that a restrictive strategy (hemoglobin $<7 \mathrm{mg} / \mathrm{dL}$ ) could be superior to a liberal strategy (hemoglobin $<10 \mathrm{mg} /$ $\mathrm{dL}$ ). Results such as these lend support to the global trend of the reduction of tolerated hemoglobin and hematocrit levels and hence the performance of fewer transfusions on these patients.

Although guidelines for transfusion practices in cardiac surgery have already been published ${ }^{[21]}$, and despite all the evidence made available during the last three decades of research, there remains great variability in the performance of transfusions among institutions and even among professionals in the same institution ${ }^{[22]}$. Over 20 years ago, Goodnough et al. ${ }^{[23]}$ study demonstrated significant variability in transfusion rates in 540 patients undergoing cardiac surgery in 18 institutions (17\% 
to $100 \%$ for packed red blood cells). In 2010, Bennett-Guerrero et al. ${ }^{[10]}$ found similar rates (7.8\% to $92.8 \%$ ) in a retrospective analysis of CABGs performed in 2008 across 798 centers. This demonstrates the lack of consensus on the level of hematocrit required to ensure the benefits of transfusion over the potential risks. The indication for transfusion derives, above all, from the personal judgment of surgeons, anesthetists and clinicians, often to the detriment of an individual's clinical condition. It is the professionals, rather than the patients themselves, who do not tolerate low levels of hemoglobin and hematocrit.

\section{Study Limitations}

The main limitation of the study relates to the reasons, aside from hemoglobin values, for blood transfusion. The reason for performing the transfusion, a surgical complication resulting in bleeding, may itself be associated with high morbidity and mortality, regardless of transfusion.

As this was a retrospective study, the results allowed us to

\section{Authors' roles \& responsibilities}

ICC Substantial contributions to the conception or design of the work; or the acquisition, analysis, or interpretation of data for the work; final approval of the version to be published

VT Substantial contributions to the conception or design of the work; or the acquisition, analysis, or interpretation of data for the work; final approval of the version to be published

HPM Substantial contributions to the conception or design of the work; or the acquisition, analysis, or interpretation of data for the work; final approval of the version to be published

MCMC Substantial contributions to the conception or design of the work; or the acquisition, analysis, or interpretation of data for the work; final approval of the version to be published

FAM Substantial contributions to the conception or design of the work; or the acquisition, analysis, or interpretation of data for the work; final approval of the version to be published

GM Substantial contributions to the conception or design of the work; or the acquisition, analysis, or interpretation of data for the work; final approval of the version to be published

JGTE Substantial contributions to the conception or design of the work; or the acquisition, analysis, or interpretation of data for the work; final approval of the version to be published

HCCS Substantial contributions to the conception or design of the work; or the acquisition, analysis, or interpretation of data for the work; final approval of the version to be published

CMCG Substantial contributions to the conception or design of the work; or the acquisition, analysis, or interpretation of data for the work; final approval of the version to be published

PSF Substantial contributions to the conception or design of the work; or the acquisition, analysis, or interpretation of data for the work; final approval of the version to be published evaluate the association between the transfusion variable and morbidity and mortality outcomes, but we cannot demonstrate causality among them. Another limitation, also related to the retrospective nature of this study, is the lack of data determining the period in which the transfusion and outcome occurred during hospitalization. Furthermore, this study used mortality from all causes as a primary outcome and did not differentiate between cardiac and non-cardiac causes of death. There is no data concerning transfusion of critical clinical patients, which are associated with higher incidence of complications.

\section{CONCLUSION}

In this study, the transfusion of blood products was found to be harmful for most patients undergoing $C A B G$, even in those with low baseline risk. Studies evaluating whether the higher incidence of complications in these patients is due to blood transfusion or to hypoxia complications are necessary to better understand transfusion practice.

\section{REFERENCES}

1. Ranucci M, Conti D, Castelvecchio S, Menicanti L, Frigiola A, Ballotta A, et al. Hematocrit on cardiopulmonary bypass and outcome after coronary surgery in nontransfused patients. Ann Thorac Surg. 2010;89(1):11-7.

2. Zindrou D, Taylor KM, Bagger JP. Preoperative haemoglobin concentration and mortality rate after coronary artery bypass surgery. Lancet. 2002;359(9319):1747-8.

3. Corwin $\mathrm{HL}$, Parsonnet KC, Gettinger A. RBC transfusion in the ICU. Is there a reason? Chest. 1995;108(3):767-71.

4. Koch CG, Li L, Duncan Al, Mihaljevic T, Loop FD, Starr NJ, et al. Transfusion in coronary artery bypass grafting is associated with reduced long-term survival. Ann Thorac Surg. 2006;81(5):1650-7.

5. Murphy GJ, Reeves BC, Rogers CA, Rizvi SI, Culliford L, Angelini GD. Increased mortality, postoperative morbidity, and cost after red blood cell transfusion in patients having cardiac surgery. Circulation. 2007;116(22):2544-52.

6. Paone G, Likosky DS, Brewer R, Theurer PF, Bell GF, Cogan CM, et al. Transfusion of 1 and 2 units of red blood cells is associated with increased morbidity and mortality. Ann Thorac Surg. 2014;97(1):87-93.

7. Mehta RL, Kellum JA, Shah SV, Molitoris BA, Ronco C, Warnock DG, et al. Acute Kidney Injury Network: report of an initiative to improve outcomes in acute kidney injury. Crit Care. 2007;11(2):R31.

8. Armitage P, Berry G, Matthews JNS. Statistical methods in medical research. $3^{\text {rd }}$ ed. Oxford: Blackwell Science; 1994.

9. Shevde K, Pagala M, Kashikar A, Tyagaraj C, Shahbaz N, lqbal M, et al. Gender is an essential determinant of blood transfusion in patients undergoing coronary artery bypass graft procedure. J Clin Anesth. 2000;12(2):109-16.

10. Bennett-Guerrero E, Zhao Y, O'Brien SM, Ferguson TB Jr., Peterson ED, Gammie JS, et al. Variation in use of blood transfusion in coronary artery bypass graft surgery. JAMA. 2010;304(14):1568-75.

11. Kremke M, Tang M, Bak M, Kristensen KL, Hindsholm K, Andreasen JJ, et al. Antiplatelet therapy at the time of coronary artery bypass grafting: a multicentre cohort study. Eur J Cardiothorac Surg. 2013;44(2):e133-40.

12. Despotis GJ, Zhang L, Lublin DM. Transfusion risks and transfusionrelated pro-inflammatory responses. Hematol Oncol Clin North Am. 2007;21(1):147-61. 
13. Fung ET, Wright GL Jr., Dalmasso EA. Proteomic strategies for biomarker identification: progress and challenges. Curr Opin Mol Ther. 2000;2(6):643-50.

14. Fransen E, Maessen J, Dentener M, Senden N, Buurman W. Impact of blood transfusions on inflammatory mediator release in patients undergoing cardiac surgery. Chest. 1999;116(5):1233-9.

15. van Hilten JA, van de Watering $L M$, van Bockel $J H$, van de Velde $C J$, Kievit $J$, Brand $R$, et al. Effects of transfusion with red cells filtered to remove leucocytes: randomised controlled trial in patients undergoing major surgery. BMJ. 2004;328(7451):1281.

16. Kuduvalli M, Oo AY, Newall N, Grayson AD, Jackson M, Desmond MJ, et al. Effect of peri-operative red blood cell transfusion on 30-day and 1-year mortality following coronary artery bypass surgery. Eur J Cardiothorac Surg. 2005;27(4):592-8.

17. Murphy GJ, Pike K, Rogers CA, Wordsworth S, Stokes EA, Angelini GD, et al. Liberal or restrictive transfusion after cardiac surgery. N Engl J Med. 2015;372(11):997-1008.

18. Engoren MC, Habib RH, Zacharias A, Schwann TA, Riordan CJ, Durham SJ. Effect of blood transfusion on long-term survival after cardiac operation. Ann Thorac Surg. 2002;74(4):1180-6.

19. Bracey AW, Radovancevic R, Riggs SA, Houston S, Cozart H, Vaughn WK, et al. Lowering the hemoglobin threshold for transfusion in coronary artery bypass procedures: effect on patient outcome. Transfusion. 1999;39(10):1070-7.

20. Hebert PC, Wells G, Blajchman MA, Marshall J, Martin C, Pagliarello G, et al. A multicenter, randomized, controlled clinical trial of transfusion requirements in critical care. Transfusion Requirements in Critical Care Investigators, Canadian Critical Care Trials Group. N Engl J Med. 1999;340(6):409-17.

21. Ferraris VA, Brown JR, Despotis GJ, Hammon JW, Reece TB, Saha SP, et al. 2011 update to the Society of Thoracic Surgeons and the Society of Cardiovascular Anesthesiologists blood conservation clinical practice guidelines. Ann Thorac Surg. 2011;91(3):944-82.

22. Stover EP, Siegel LC, Parks R, Levin J, Body SC, Maddi R, et al. Variability in transfusion practice for coronary artery bypass surgery persists despite national consensus guidelines: a 24-institution study. Institutions of the Multicenter Study of Perioperative Ischemia Research Group. Anesthesiology. 1998;88(2):327-33.

23. Goodnough LT, Johnston MF, Toy PT. The variability of transfusion practice in coronary artery bypass surgery. Transfusion Medicine Academic Award Group. JAMA. 1991;265(1):86-90. 